\title{
Levão Bogossian, o estimulador da cirurgia cientifica
}

\section{Levão Bogossian, the fomenter of scientific surgery}

\author{
ECBC-RJ Umberto Perrotta
}

$T^{\prime}$ ranscorria o ano de 1944 quando conheci o Prof. Levão Bogossian, então aluno do $4^{\circ}$ ano da Faculdade Nacional de Medicina. Eu cursava o $3^{\circ}$ ano na mesma faculdade e iniciava o internato em cirurgia no Hospital Moncorvo Filho, Serviço do Prof. Castro Araújo. Levão já era interno do Serviço do Prof. Ugo Pinheiro Guimarães. Mantínhamos diariamente um contato quando falávamos sobre os casos cirúrgicos então internados.

Quando atingimos o $5^{\circ}$ ano, fizemos concurso para a função de Auxiliar Acadêmico da Secretaria de Saúde da antiga Prefeitura do Distrito Federal (PDF) e, posteriormente, o concurso para médico da PDF, sendo eu designado para o atual Hospital Souza Aguiar e o Professor Levão para o Hospital Getúlio Vargas.

É uma tendência natural do Espírito Humano procurar (ou crer possuir) a teoria que engloba tudo em um instrumento prático que resolva todos os problemas. Lamentavelmente essa tendência é forte, levando as pessoas a esquecer a dura realidade das contradições restabelecedoras de todos os equilíbrios ${ }^{1}$ a que está submetido o ser humano quando procura simplificar o fenômeno orgânico, mas a natureza se opõe, complicando-os. O homem está longe da verdade, pois não a conhece e assim, não pode defini-la, conceituá-la. Isso acontece porque está sempre longe da maturidade. Daí, a necessidade de atualizar-se, de aperfeiçoar-se. Esta é a grande missão do Educador. Foi a grande missão de Levão Bogossian.

As primeiras experiências educacionais tinham como essência o enquadramento da criança no aprendizado junto aos mais antigos da comunidade onde estava integrada. A criança imitava os mais velhos. E não estamos hoje em dia muito longe disso. O que foi a Cátedra se não a repetição dessa caraterística dos povos primitivos?

O que é o Chefe de Escola da Universidade Moderna? É a cópia, melhorada, dessa prática das sociedades primeiras, rudimentares. No ensino é o assistente intelectual imitando seu professor, o seu guia, o seu chefe intelectual, cultural; até social pela substituição da organização política e pela formação de uma linguagem escrita e pela literatura.

A transição da sociedade primitiva para os primeiros estágios da civilização é assinalada pela substituição da organização genética da sociedade pela organização política e pela formação de uma linguagem e de uma literatura. A sociedade organizada politicamente faz com que haja reconhecimento do individualismo. O individuo passa a ser unidade social.

Os gregos foram os primeiros a desenvolverem a personalidade e o fizeram incentivando a educação. Os espartanos estruturaram o desenvolvimento do aspecto social da educação e foram, talvez, os primeiros a valorizar a educação de toda a sociedade. Coube aos gregos exaltar o prazer estético, o poder intelectual, a personalidade moral, a liberdade política, enfim, a cultura.

A mentalidade dos romanos era inteiramente prática, e o lar era a grande escola, sendo supremo o poder paterno, a família, a unidade social responsável pela educação moral e cívica da criança. O pater famílias tornava-se o grande educador, e a família, uma grande unidade social. Mas a posição da mulher, de inteligência e responsabilidade, não se apoiava nas amas ou escravas. Uma vez nascido, o filho não era entregue a um escravo responsável por sua educação, (em grego, o pedagogo),

É este o retrato da família dos professores Levão e Terezinha Bogossian. A escola que os dois fundaram. E Levão, o grande patriarca, assim reconhecido pela família até nos convites póstumos para as cerimônias religiosas que Ihe foram dedicadas. Levão Bogossian deixou a imagem de um homem de bem, já que o a filosofia reconhece o bem como a parte mais elevada da natureza, isto é, a razão., o que leva ao bem ser e ao bem fazer. Como homem de bem, o que depende da boa conduta, Levão Bogossian dominava o bem ser e o bem fazer, $\mathrm{O}$ bem ser é o bem do intelecto ligado à posse da verdade universal da escola platônica e proporciona o desenvolvimento e o bem estar do indivíduo, Do bem fazer surge a felicidade da expressão e do nível de Levão Bogossian..

Levão Bogossian descende de um ilustre médico, Dr. Bogos Bogossian, que em sua época não somente exercia a medicina, como também ensinava-a.

Deu-nos o casal, Profa. Anita e Dr. Bogos Bogossian, uma geração de brilhantes brasileiros, que sobressaíram todos sem exceção; na vida política, sócio cultural e docente de nosso país. Houve época em que ser amigo de um Bogossian significava poder político. Confidenciava-me porém o estimado amigo Levão: "isto é uma ilusão, o poder é transitório, Precisamos trabalhar, retribuir o que recebemos de apoio, dedicando-nos com afinco às nossas atividades profissionais. Nisto sim, consiste o desenvolvimento nacional".

1 O homem está submetido às contradições reestabelecedoras de todos os equilíbrios 
Jamais o Prof. Levão pensou em beneficiar-se da intimidade com o poder. Sempre recusou-se a ocupar altos cargos na administração federal. De uma feita, submeteu-se, com outros colegas de universidade, ao concurso para Professor Titular de Clínica Cirúrgica da Faculdade de Medicina da Universidade Federal do Rio de Janeiro. Foi aprovado com destaque. Houve uma série de mandados de segurança impetrados pelos livre-docentes fundamentados na legislação de então, que igualava o concurso de professor titular ao de livre docente. Amigo íntimo de ministros de Estado, e de alguns, médico particular, negou-se a requerer administrativamente a nomeação para Professor Titular, já que tinha sido aprovado em concurso público de títulos e provas. Disse que só o faria se todos os demais professores aprovados fossem nomeados. Preferiu submeter-se a novo concurso público, quando foi o grande vitorioso, tendo eu participado da Comissão Examinadora.

A vida do grande cirurgião e professor firma-se em exemplos paralelos a esse, onde o desempenho cirúrgico é fruto de seu caráter, mas também da escola cirúrgica que frequentou.

O grande impulso à cirurgia se deve indiscutivelmente a William Stewart Halstead que instalou na John's Hoppkins Medical School, no Departamento de Cirurgia, o Laboratório de Cirurgia Experimental. A cirurgia deixava de ser empírica para ser científica. Hoje não se pode admitir, não se pode aceitar Centro Cirúrgico sem Laboratório de Pesquisa Experimental.

A Pesquisa Experimental estabeleceu as Bases Científicas da Cirurgia, essencial e fundamental para os conhecimentos fisiopatológicos do processo cirúrgico e obviamente, para um tratamento racional e científico. Levão Bogossian, herdeiro científico de Ugo Pinheiro Guimarães, desenvolveu as Bases Científicas da Cirurgia com seus livros, trabalhos e pesquisas sobre Choque, Choque Séptico, Transfusão de Sangue, Traumatismos Toráxicos, Pré e Pós-Operatório e Autotransfusão. Foi o professor da disciplina Bases Científicas da Cirurgia do Curso de Pós Graduação em Cirurgia, na Faculdade de Medicina da Universidade Federal do Rio de Janeiro.

Como dizia Levão, o cirurgião, hoje, deve ir além das fronteiras básicas da anatomia, da embriologia e da clínica cirúrgica. Não pode estar familiarizado somente com a macroscopia. Não deve deve conhecer somente o que se passa na célula, mas também as reações químicas na molécula, no átomo, e especificamente, no elétron. É a biologia molecular modificando todos os nossos conhecimentos sobre a evolução das doenças, inclusive do enveIhecimento.

E vamos, mais uma vez, encontrar Levão Bogossian, o grande estudioso, pesquisando, publicando, falando sobre os Novos Mediadores Humorais, na Resposta Endócrina e Metabólica no Trauma.

Foi um Mestre, aquele que seus discípulos reconhecem como tal. E situam-no no lugar da sabedoria, esperando a revelação de alguma verdade. Ele, por sua vez, deve dar provas, constantemente, de se achar à altura da função que aceita encarnar,

Levão Bogossian foi o grande mestre, o grande didata, o grande chefe de escola. Suas aulas, entusiasmando os alunos, eram aplaudidas. Usava discurso claro, preciso, e elucidativo.

$\mathrm{Na}$ longa carreira docente jamais deixou de ministrar uma aula que lhe coubesse. Lutou tenazmente em todos os escalões da Universidade Federal do Rio de Janeiro para aumentar o número de aulas no currículo de cirurgia. Era um obstinado nos ideais universitários. Nas reuniões da Congregação da Faculdade de Medicina, sempre solicitava a palavra para reclamar do pequeno espaço destinado ao ensino da Cirurgia.

O prof. Levão Bogossian teve uma carreira docente-universitária das mais brilhantes. Suas qualidades profissionais demonstraram-se desde a Faculdade de Medicina, quando ensinava a seus colegas de turma, temas de Técnica Operatória e Cirurgia Experimental.

$\mathrm{Na}$ Faculdade de Medicina mostrou uma trajetória de mérito. Ocupou todos os cargos da carreira docente: Instrutor de Ensino, Professor Auxiliar, Professor Assistente e Professor Titular. Foi, também, livre docente de Cirurgia da Escola de Medicina e Cirurgia da UNIRIO e exerceu o magistério médico na Faculdade de Ciências Médicas da UERJ. Demitiu-se dessas instituições universitárias para concentrar as atividades docentes na Universidade Federal do Rio de Janeiro

No Departamento de Cirurgia de Faculdade de Medicina da UFRJ foi: Coordenador didático, Coordenador adjunto de Pós Graduação, Chefe do Departamento de Cirurgia por três mandatos, fato raro na UFRJ.

Como Chefe do Departamento de Cirurgia, estimulou o ensino de Pós Graduação e Programas de Educação Continuada. Lutou tenazmente pela melhoria dos cursos de Pós-graduação sensu stricto e sensu lato. Para tanto, todas as parcas verbas destinadas ao Departamento de Cirurgia eram totalmente aplicadas no Laboratório de Cirurgia Experimental, contribuindo assim para o desenvolvimento da Pesquisa Experimental em Cirurgia. Havia um total entrosamento entre a Direção da Faculdade de Medicina (Prof ${ }^{a}$ Vera Halfoun), a Chefia do Departamento de Cirurgia e a Coordenação de Pós- Graduação em Cirurgia.

O Prof. Levão Bogossian legou-nos produção técnico-científica invejável. Contam-se às centenas seus artigos científicos, publicados e apresentados em Congressos Médicos Nacionais e Internacionais. Era Membro Convidado dos grandes eventos científicos. Teve oportunidade de fazer conferências em quase todas as cidades do Brasil, além de múltiplas no exterior. Era Membro Emérito do Colégio Brasileiro de Cirurgiões, Membro da Sociedade de Medicina do Rio de Janeiro e da Sociedade de Gastroenterologia do Rio de Janeiro. Foi eleito para a Academia Nacional de Medicina e empossado em 3-8-93, mostrando uma atuação brilhante nesta entidade, sendo um dos mais assíduos frequentadores, permantemente so- 
licitava a palavra para discutir os assuntos em pauta. Por duas vezes foi eleito Presidente da Secção de Cirurgia, convidando-me para ser o Secretário da Secção.

Fez parte da Comissão Organizadora do Curso de Cirurgia de Tireóide ministrado na Sociedade de Medicina e Cirurgia do Rio de Janeiro. Posteriormente na Academia Nacional de Medicina, participou do Curso de Urgências Abdominais durante 46 anos.

Os livros sobre Choque, Choque Séptico, Pré e Pós-Operatório, Traumatismo Torácico e Autotransfusão são de sua autoria exclusiva. Uma de suas obras mais conhecidas, o livro sobre Choque, encontra-se na $3^{\text {a }}$ edição e foi vertido para a língua espanhola. Com o conjunto da obra, torna-se um dos grandes divulgadores da ciência cirúrgica nacional no exterior.

Sempre professor, orientou diversas teses de mestrado e doutorado, e participou de múltiplas bancas de exame de concurso para o magistério superior.

Levão Bogossian, como moderador de Mesa Redonda, tornava-se o grande participador, ao levantar problemas, questionar, fomentar discussões científicas entre os conferencistas e o plenário. Revela-se, nestes momento, o poder de sua cultura, e a profundidade de seus conhecimentos científicos. Em virtude disso, foi sempre aplaudido por conferencistas e pelos assistentes.

Levando seus conhecimentos além dos muros da universidade, proporcionou e estimulou um dos maiores objetivos dessa: a extensão. Disseminou e difundiu suas qualidades didáticas no Hospital Getúlio Vargas, onde implementou os princípios científicos e modernos da cirurgia. Sua equipe era cortejada, solicitada na era dignificante da Assistência Hospitalar Pública. Contam-se às dezenas os cirurgiões oriundos da Escola Cirúrgica de Levão Bogossian. Estão disseminados pelo Brasil e pela Iberoamérica.

Quando da aposentadoria compulsória do magistério médico oficial, recebeu o Prof. Levão Bogossian uma programação extensa de homenagens as quais compareceram centenas de amigos.

Por sua inestimável contribuição ao ensino, à pesquisa e à extensão, o Departamento de Cirurgia da UFRJ, por unanimidade, propôs o título de emérito ao ilustre mestre, aprovado, em todas as instâncias da UFRJ, por unanimidade.

O Prof. Levão Bogossian deve muito de seu currículo ao apoio e estímulo permanente que lhe deu a Profa. Therezinha de Jesus da Torre Bogossian sua esposa, enaltecedora do quadros docentes da UNIRIO. Nas horas difíceis, ela foi apoio e afeto. Foi força e doçura para todos os filhos, guardiã dos deveres e dos sentimentos, é modelo para todos os que merecem sua amizade.

Levão Bogossian, o inesquecível Levão, nos deixou seu exemplo. Deixou-nos o companheirismo nas horas difíceis, e seu sorriso bem humorado. A mão amiga e o caminho de uma vida honrada e luminosa. Por tudo isso, obrigado, Levão! 